\title{
Review
}

\author{
Volker Kiefel*
}

\section{Platelet antibodies in immune thrombocytopenia and related conditions}

https://doi.org/10.1515/labmed-2020-0012

Received February 2, 2020; accepted March 16, 2020

\begin{abstract}
Platelet autoantibodies are a common finding in immune thrombocytopenia (ITP) and in rare cases of antibody-mediated platelet function ("acquired thrombasthenia"). In drug-induced immune thrombocytopenia, antibodies react with platelets only in the presence of the offending drug. Alloantibodies reacting with platelets are induced by transfusion of cellular blood products or during pregnancy. They are responsible for fetal/neonatal alloimmune thrombocytopenia (FNAIT), they are able to cause febrile, nonhemolytic transfusion reactions and they give rise to insufficient platelet increments following platelet transfusions. Two rare transfusion reactions: post-transfusion purpura (PTP) and passive alloimmune thrombocytopenia (PAT) are triggered by platelet alloantibodies. This review discusses the clinical value of tests for platelet antibodies in various clinical situations related to insufficient primary hemostasis.
\end{abstract}

Keywords: alloimmunization; drug-induced immune thrombocytopenia; fetal and neonatal alloimmune thrombocytopenia; immune thrombocytopenia; immunoassay; platelet antibody; post-transfusion purpura; transfusion reaction.

\section{Brief summary}

Platelet antibodies are responsible for accelerated elimination of platelets in immune thrombocytopenia, immunemediated neonatal thrombocytopenia and transfusion reactions. Currently, glycoprotein-specific immunoassays are used for antibody screening and detection.

\footnotetext{
*Correspondence: Prof. Dr. med. Volker Kiefel, Institut für Transfusionsmedizin, Universitätsmedizin Rostock, Ernst-Heydemann-Str. 6, 18057 Rostock, Germany, E-Mail:volker.kiefel@uni-rostock.de
}

\section{Introduction}

Platelets play a central role in primary hemostasis. Patients with both qualitative and quantitative alterations of platelets are often prone to enhanced bleeding. Thrombocytopenia, the most common quantitative platelet aberration, can result from reduced thrombocytopoiesis, enhanced platelet destruction, consumption or enhanced pooling in an enlarged spleen. Platelet antibodies may induce thrombocytopenia in conditions such as immune thrombocytopenia (ITP), fetal or neonatal alloimmune thrombocytopenia (FNAIT) and post-transfusion purpura (PTP) and they may affect platelet increments in alloimmunized recipients of platelet transfusions. Platelet antibodies may induce alterations of platelet function without thrombocytopenia.

In contrast to assays for red cell antibody identification, modern and advanced methods for platelet antibody detection are glycoprotein (GP)-specific. They allow binding of antibodies with isolated proteins or with target GPs in the native platelet membrane labeled with (mouse) monoclonal antibodies (moAb).

Platelet autoantibodies appear spontaneously or after unspecific alterations of the immune status: during infections, after vaccinations or together with the immunologic changes related to allogeneic bone marrow transplantation. They do not only react with patients' own platelets, they usually recognize the corresponding antigens on platelets of healthy individuals, if these platelets express these target antigens. In contrast, alloantibodies result from specific immunization with allogeneic platelet. This may affect patients receiving transfusions of cellular blood products containing platelets or even traces of platelet membranes and this may occur in pregnant women following fetal-maternal transfer of platelets. Platelet alloantibodies react with genetic variants of a platelet GP and - with the exception of PTP - they do not bind to autologous platelets. Current platelet alloantigen nomenclature uses the designation "HPA" (for human platelet antigen), followed by a number and an allele designation $[1,2]$. Patients lacking a platelet membrane GP may form isoantibodies following pregnancies or transfusion of 
blood products. These isoantibodies usually react with monomorphic determinants on platelet GPs.

In addition to the platelet-specific HPA antigens, also blood group ABH determinants and HLA class I antigens are expressed on platelets, so both blood group-specific isoagglutinins and HLA class I antibodies react with platelets. This has major implications for immunologic testing of platelet antibodies and for the immunologic compatibility of platelet transfusions.

\section{Principles of platelet antibody testing}

\section{First-generation assays}

In the past, various attempts for platelet antibody testing were made employing diverse techniques: platelet agglutination [3], platelet complement fixation [4], platelet serotonin release test [5], inhibition of clot retraction [4]. These first-generation assays are based on the observation of secondary effects elicited by antibody binding to platelets. These assays depend upon platelet activation or other secondary effects, or they require that these antibodies activate complement after binding to platelets. They are no more used as diagnostic tools for platelet autoantibodies or alloantibodies. The only exception are the ${ }^{14} \mathrm{C}$ serotonin release assay which is used for the laboratory diagnosis of heparin-induced thrombocytopenia (HIT) [6] and the heparin-induced platelet activation (HIPA) assay which follows a similar principle [7].

\section{Second-generation assays}

Second-generation platelet antibody tests are based on qualitative assessment or quantitative measurement of immunoglobulin binding to platelets. These techniques make use of anti-human globulin antibodies raised in animals. Sera with anti-human globulin were introduced by Coombs et al. for red blood cell (RBC) antibody testing [8]. Semiquantitative measurement of platelet antibodies was described by Mueller-Eckhardt et al. [9] who used radioactively labeled anti-human globulin: platelet radioactive anti-immunoglobulin test (PRAT). Similarly, platelets suspended in buffered isotonic saline may be incubated with serum, washed and incubated with alkaline phosphatase-labeled anti-immunoglobulin G (IgG) (platelet suspension enzyme-linked immunosorbent assay [ELISA]), for details see [10]. A widely used assay, the platelet suspension immunofluorescence test (PSIFT) was described by von dem Borne et al. [11]. These authors reduced "background" fluorescence of platelets due to nonspecific binding of immunoglobulin or immune aggregates to platelets by paraformaldehyde fixation of test platelets prior to incubation with serum [12]. PSIFT is used as one of the reference methods for platelet antibody testing using intact platelets. However, the PSIFT fails to detect antibodies recognizing antigens expressed with very low density, e.g. anti-HPA-5a/b and anti-HPA-15a/b. Immunofluorescence may be analyzed by flow cytometry or with a fluorescence microscope. A variant of this method is the platelet adhesion immunofluorescence test (PAIFT) [13]. Here, fresh or cryopreserved platelets are allowed to attach to the surface within reaction fields on flat glass micotrays.

Another assay for testing IgG binding to intact platelets, which was developed in Japan and is still widely used in Asian laboratories, is the mixed passive hemagglutination assay (MPHA) [14]. Here, platelets or platelet membrane extracts are attached to the surface of roundbottomed microtiter plates and they are incubated with the serum. After washing the wells, a suspension of indicator cells (sheep RBCs coated with anti-IgG) is added to these wells. After spontaneous sedimentation of the indicator cells, wells coated homogeneously with indicator cells indicate a positive reaction, whereas indicator cells concentrated in a small point or ring at the bottom of the well indicate a negative reaction [15].

A common problem with this category of tests arises with the analysis of platelet-specific alloantibodies in sera of highly immunized patients with both platelet-specific and HLA class I antibodies. As HLA class I antigens are also expressed in high density on the platelet membrane, reaction patterns of such sera with different test platelets often do not allow identification of antibody specificities. One possible solution was proposed by Nordhagen et al. who observed that the reactivity of HLA class I antibodies was removed by previous chloroquine treatment of platelets [16]. Testing of sera with chloroquine-treated platelets was abandoned with the availability of third-generation, GP-specific tests.

For detection of alloantibodies, sera are tested with panels of donor platelets with different platelet alloantigen combinations. As ABH determinants are expressed on platelets [17, 18], test platelets should be from blood group $\mathrm{O}$ donors, in order to avoid reactions due to IgG anti-A or anti-B. This is also necessary for the GP-specific tests below, as $\mathrm{ABH}$ determinants have been identified on platelet GPs [19, 20]. 
Tests for platelet antibodies may be qualitative with results reported as "negative" or "positive" or results may be described with a scoring system (with possible values $0,1 \ldots 4$ for negative results, weak to strong reactions). This approach is used by many laboratories for reporting results in (indirect) platelet immunofluorescence or ELISA tests.

Quantitative measurements for antibodies bound to platelets have been attempted by measurement of IgG in platelet lysates [21]. However, platelet alpha granules carry significant quantities of immunoglobulins and other plasma proteins and these "nonspecific" antibodies are not involved in immune reactions against these platelets [22]. Quantitative measurement of platelet surface IgG was tried by several groups using competitive antihuman IgG binding assays. The first assay (complement lysis inhibition assay) described by Dixon et al. in 1975 [23] found very high IgG quantities on the platelet surface (200-400 fg/platelet), which were not confirmed by other authors. Using a quantitative, competitive immunoassay (competitive enzyme-linked immunoassay [CELIA]) our group found the IgG quantity on the platelet surface to be lower than $1.8 \mathrm{fg} /$ platelet [24]. Similar quantities were found by Follea et al. [25] and Kelton and Denomme [26]. One femtogram of IgG is approximately equivalent to 4000 molecules, so $2000-6000$ molecules are detectable on the surface of a platelet from a normal subject [27] and on test platelets after incubation with serum without platelet antibodies. If this IgG quantity is determined on the patients' autologous platelets, this is often referred to as platelet-associated IgG (PAIgG). These competitive, quantitative immunoassays were also used for the determination of free platelet antibodies in plasma.

\section{Third-generation assays}

With increasing demands for efficient and precise platelet antibody testing, efforts were made to discriminate reactions of platelet reactive antibodies against different structures of the cell membrane. As an example, HLA class I antibodies will react with platelets, but they play no or only a minute role in the pathogenesis of FNAIT or PTP. In contrast, antibodies against GP IIb/IIIa, Ib/IX and, to some extent, GP Ia/IIa and CD109 are implicated in most cases of FNAIT. HLA class I antibodies are common in female patients after previous pregnancies; they may also occur after previous transfusion.

Antigen-specific testing is achieved with third-generation assays which provide information on the protein recognized by platelet antibodies. Among the first attempts were immunoblotting [28] and radioimmunoprecipitation [29]. Due to the fact that sodium dodecyl sulfate (SDS) treatment destroys a considerable fraction of epitopes recognized by platelet alloantibodies and by autoantibodies, immunoblotting is no more used for platelet antibody detection. Immunoprecipitation has been used for scientific studies of platelet antibodies. So, the molecular basis of the HPA-5 [29] and the HPA-15 [30] alloantigen systems has been characterized by radioimmunoprecipitation. But as these techniques are extremely time-consuming, they play no role in the routine immunohematological laboratory.

As soon as well-defined moAb against platelet GPs became available, it seemed attractive to try a "sandwichimmunoassay" with a moAb attached to the solid phase of microtiter plates. These moAb were allowed to capture GP IIb/IIIa or GP Ib/IX from a platelet lysate. The wells were then incubated with plasma/serum samples and autoantibodies were then detected with radiolabeled antihuman IgG [31, 32]. However, this assay was rather insensitive due to high background signals. This is the result of unspecific binding of IgG to the solid phase. This problem was circumvented with the monoclonal antibody-specific immobilization of platelet antigens (MAIPA) [33, 34] and immunobead assays [35]. The principle of the (indirect) MAIPA assay is explained in Figure 1. MAIPA has been used in many laboratories and many new alloantibody specificities have been discovered using this technique, especially those against low-frequency alloantigens. This test principle was later applied to tests for antibodies against granulocytes [36], endothelial cells [37], RBCs [38] and for HLA class II antibodies [39]. The MAIPA assay and immunobead assay have the advantage that the human antibodies bind to epitopes on platelet GPs in their natural configuration in the platelet membrane. This makes them potentially more sensitive than assays using isolated GPs attached to solid-phase materials [27]. Assays following a similar principle are modified antigen capture ELISA (MACE) [40] and simultaneous analysis of specific platelet antibodies (SASPA) [41].

In addition to these in-house assays, commercial GPspecific assays have been developed: the PakPlus ELISA (Immucor, Dreieich, Germany) and the bead-based PakLx immunoassay (Immucor, Dreieich, Germany). The PakLx assay is based on a suspension of beads ("microspheres") carrying different GPs with different HPA phenotypes. They are incubated simultaneously with the serum sample to be tested, the beads are then washed and incubated with anti-human IgG labeled with a fluorescent dye. The Luminex instrument (Luminex Corporation, Austin, TX, USA) identifies the specific microspheres by 


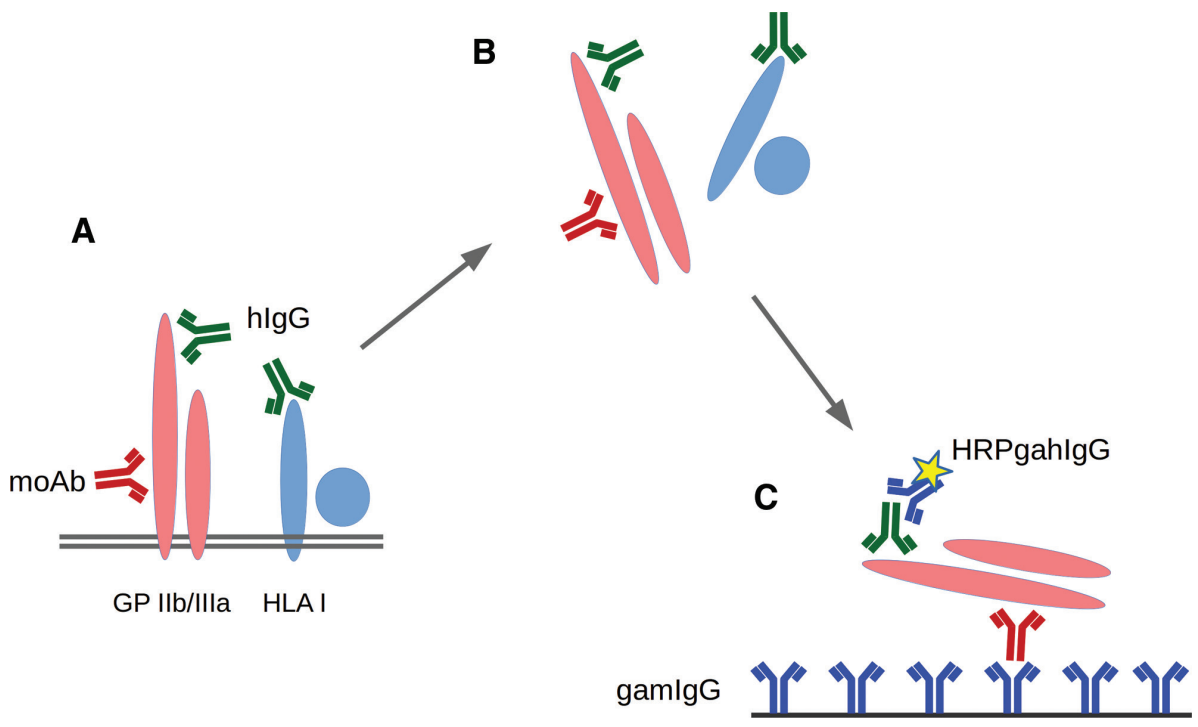

Figure 1: Principle of the MAIPA assay.

Panel A shows a small section of the cell membrane of an intact platelet. Platelets are first incubated with the serum to be tested, apparently (human) antibodies (hlgG) react with GP IIb/IIla and HLA class I molecules. In this experiment, antibodies against GP IIb/IIla are of interest: after washing the platelets, they are incubated with a mouse monoclonal antibody against GP IIb/IIla, which should react with an epitope different from the binding site recognized by the human antibody. After a further washing step, platelets are solubilized with a nonionic detergent (B), the lysate is then centrifuged in order to remove particulate material and the supernatants of the lysate are transferred to a microtiter platelet coated with goat anti-mouse IgG (C). The moAb-labeled GP IIb/IIla will be fixed to the microtiter plate, whereas the unbound HLA I molecule will get lost during the next washing step. The (human) anti-GP IIb/IIla will be detected with conventional ELISA technology with an enzyme-labeled goat anti-human IgG (HRPgahlgG).

analyzing their color and it analyzes the fluorescence signals associated with different beads indicating the quantity of IgG bound to these beads. The same principle is used to characterize HLA class I antibodies using single antigen bead tests. Compared to the PakLx technique, MAIPA is more time-consuming and requires skilled technicians. The PakLx assay has been compared to MAIPA, and the results are comparable for most antibody specificities [42]; in some sera, HPA-3a antibodies are missed by PakLx [43].

Even GP-specific tests currently in use have shortcomings. Some maternal FNAIT-sera apparently contain HPA-1a antibodies with low avidity, which are not detected in GP-specific assays with several washing steps. One possible solution is a technique based on purified GP IIb/IIIa bound to a microchip which allows to study the binding kinetics low-avidity anti-HPA-1a (surface plasmon resonance: SPR) [44]. Other problems relate to the fact that platelets with extremely rare alloantigens are not readily available for antibody testing. One possible solution are bioengineered cell lines which may be tested by flow cytometry or with GP-specific assays [45]. Such cells are also useful for the detection of HPA-15 antibodies, which can be detected only with difficulties in platelet-based assays due to the extremely low expression of CD109 on platelets $[45,46]$.

\section{Indirect and direct platelet antibody tests}

"Free" platelet autoantibodies and alloantibodies may be determined in serum or in plasma with tests using intact platelets or with GP-specific tests. In patients with immune thrombocytopenic purpura (ITP), platelet autoantibodies may be detected in the patients' plasma, and on the patients' autologous platelets (PAIgG). This situation is analogous to that in RBC autoantibody testing in patients with autoimmune hemolytic anemia. RBC autoantibodies on the patients' red cells are detected with the direct antiglobulin test (formerly named the direct Coombs test). PAIgG can be determined on the patients' intact autologous platelets using qualitative (e.g. platelet immunofluorescence) or quantitative tests, e.g. competitive immunoassays [24]. As discussed below, GP-specific tests are more appropriate for the assessment of plateletbound autoantibodies (“GP-PAIgG": GP-specific IgG) [47].

\section{Additional techniques: eluates, immunological crossmatch tests, quantitation of anti-HPA-1a, platelet antigen (HPA) typing}

A supplementary technique used for the characterization of platelet antibodies is the elution of antibodies from 
the platelet membrane followed by characterization in one of the assays described above. The principle of our own technique is described in [47]. In brief, platelets with bound antibodies are incubated in buffer with $\mathrm{pH} 2.8$ for $5 \mathrm{~min}$, platelets are spun down by centrifugation and the supernatants with the eluted antibody are pipetted into a separate tube and neutralized with Tris buffer to $\mathrm{pH}$ 7.2. This neutralized eluate can be analyzed with a test for platelet antibodies. This technique has been used to characterize PAIgG and a combined strategy of adsorption/ elution can be applied to separate alloantibody specificities in sera containing complex antibody mixtures.

Normally, antibody screening and identification is performed with a platelet test panel. This is a collection of platelets or platelet GP preparations which comprises all relevant platelet GPs so that most platelet alloantibodies will be identified. In serological/immunological platelet crossmatch assays, serum is tested with platelets from a certain individual. This is often done to test the immunological compatibility of a platelet concentrate for an immunized patient. Platelet crossmatches are also part of the immunological workup of possible cases of FNAIT.

Quantitative measurement of anti-HPA-1a using MAIPA has been established in order to investigate a possible correlation between antibody concentration and fetal or neonatal thrombocytopenia in FNAIT. Therefore, optical densities (ODs) of serial dilutions of the test serum and a reference standard serum are plotted against dilutions in a semilogarithmic chart. The concentration is derived from the mean distance between the regression curves at three or four OD. Results are expressed in arbitrary units (AU) [48] or international units (IU) [49]. The World Health Organization (WHO) International Standard anti-HPA-1a Serum (100 IU/mL) is available from NIBSC, UK. Quantitative measurements of anti-HPA-1a are recommended by some authors for the prediction of fetal thrombocytopenia in immunized pregnant women [50].

The determination of HPA antigens was first done with serological methods. Today, as the genetic basis of HPA-1a/b [51] and of all other HPA "antigen systems" has been investigated, HPA-antigen typing is done by DNAbased methods. Most HPA polymorphisms are the result of single-nucleotide polymorphisms.

\section{Tests for drug-dependent antibodies}

Drug-dependent platelet antibodies (DDABs) are a specific finding in patients with drug-induced immune thrombocytopenia (DIT). This is a special species of autoantibodies reacting with (autologous) platelets in the presence
Table 1: Interpretation of immunoglobulin binding assays for the detection of drug-dependent antibodies.

\begin{tabular}{llll}
\hline $\begin{array}{l}\text { Drug } \\
\text { (or metabolite) }\end{array}$ & Serum & Reaction & Interpretation \\
\hline+ & Patient & + & $\begin{array}{l}\text { Drug-dependent } \\
\text { antibody }\end{array}$ \\
- & Patient & - & \\
+ & Normal donor serum & - & \\
- & Normal donor serum & - & \\
+ & Patient & + & Platelet \\
- & Patient & + & alloantibody, \\
+ & Normal donor serum & - & autoantibody \\
- & Normal donor serum & - & \\
+ & Patient & + & Nonspecific \\
- & Patient & - & adsorption of Ig to \\
+ & Normal donor serum & + & platelets induced \\
- & Normal donor serum & - & by the drug \\
+ & Patient & - & Negative result \\
- & Patient & - & \\
+ & Normal donor serum & - & \\
- & Normal donor serum & - & \\
\hline
\end{tabular}

of drugs which apparently induced thrombocytopenia. "True" drug-dependent antibodies have to be discriminated from normal platelet antibodies. Only if "incomplete" control experiments yield a negative result and the complete assay (platelets, patient's serum, drug added) shows antibody binding to platelets, a drug-dependent antibody has been identified. Details are shown in Table 1. Drug-dependent antibodies have been observed with various drugs, sometimes only metabolites of drugs were responsible for DIT [52, 53], which makes testing even more complicated as drug metabolites are often not easily available for testing. For screening purposes, urine from normal subjects or patients ingesting the drug may be used as "raw" metabolite preparation [53]. However, this approach will work only if metabolites of a drug are renally excreted. Drug-dependent antibodies have been detected with complement fixation tests, platelet immunofluorescence tests and ELISA tests with platelets in suspension. As DDABs react with the same platelet GPs as autoantibodies, GP-specific assay as the MAIPA assay may be used as well to find DDABs against GP IIb/IIIa or GP Ib/IX.

\section{Platelet antibodies in different clinical conditions}

Alloantibodies may react with different membrane structures expressed on platelets. It has been known for a long time that $\mathrm{ABH}$ determinants $[17,18]$ are expressed 
Table 2: Important human platelet alloantigens (HPA).

\begin{tabular}{llrl}
\hline Antigen & $\begin{array}{l}\text { Molecular } \\
\text { localization }\end{array}$ & $\begin{array}{r}\text { Phenotype } \\
\text { frequency }\end{array}$ & $\begin{array}{l}\text { Population, } \\
\text { reference }\end{array}$ \\
\hline HPA-1a & GP IIIa (GP IIb/IIIa) & $97.5 \%$ & Germany [55] \\
HPA-1b & & $30.8 \%$ & \\
HPA-2a & GP Ib $\alpha$ (GP Ib/IX) & $99.8 \%$ & Germany [55] \\
HPA-2b & & $11.8 \%$ & \\
HPA-3a & GP IIb (GP IIb/IIIa) & $86.1 \%$ & Germany [55] \\
HPA-3b & & $62.9 \%$ & \\
HPA-4a & GP IIIa (GP IIb/IIIa) & $>99.9 \%$ & Germany [55] \\
HPA-4b & & $<0.1 \%$ & \\
HPA-4a & & $>99.7 \%$ & Japan [56] \\
HPA-4b & & $1.7 \%$ & \\
HPA-5a & GP Ia (GP Ia/IIa) & $98.8 \%$ & Germany [55] \\
HPA-5b & & $20.7 \%$ & \\
HPA-15a & CD109 & $80.5 \%$ & UK [57] \\
HPA-15b & & $60.2 \%$ & \\
\hline
\end{tabular}

on platelets. As A- and B-determinants are expressed on several platelet GPs, anti-A and anti-B antibodies especially of the IgG class will yield positive reactions also in GP-specific tests for platelet antibodies [19]. Moreover, HLA class I antigens are expressed in large quantities on platelets [54]. ABH determinants are not only expressed on red cells and platelets, but on cell membranes of many tissues ("histo blood groups"). Also HLA class I antigens are expressed on cells of many tissues. The term platelet-specific alloantigens refers to determinants on membrane GPs exclusively or predominantly expressed on platelets and megakaryocytes. In the context of this review, we consider alloantibodies reacting with determinants on GPs IIb/IIIa, Ib/IX, Ia/IIa and CD 109 as "platelet specific": they are the crucial laboratory finding in maternal sera of cases of FNAIT. A list of relevant platelet alloantigens is given in Table 2. Platelet autoantibodies react with GP IIb/IIIa and components of the GP Ib/IX/V complex.

Often, the term isoantibody is used synonymously to alloantibody. In the context of immunohematology, alloantibodies are those formed by individuals lacking a certain antigenic protein following immunization with normal blood cells. A typical example in the field of platelet immunology are isoantibodies against GP IIb/IIIa in patients with type I Glanzmann's thrombasthenia (GT).

\section{Fetal/neonatal alloimmune thrombocytopenia}

FNAIT is the "platelet equivalent" to hemolytic disease of the newborn [58]: pregnant women are immunized against platelet alloantigens on fetal platelets. IgG alloantibodies are then transferred through a neonatal Fc-receptor (FcRn)-mediated mechanism to the fetal circulation. A critical complication of the ensuing fetal thrombocytopenia is cerebral hemorrhage.

Most FNAIT cases are caused by antibodies against platelet-specific alloantigens (HPA antigens). Table 3 lists antibody specificities identified in cases of FNAIT investigated in a German center. Alloimmune thrombocytopenia in a newborn can be suspected, if other cases for neonatal thrombocytopenia (sepsis, infection, hereditary thrombocytopenia) seem improbable. In Caucasian populations, FNAIT is most commonly related to a maternal HPA-1a antibody (approximately $75 \%$ of cases: Table 3 ). In these cases, the mother is of the HPA-1a negative (i.e. HPA- $1(\mathrm{a}-\mathrm{b}+)$ ) phenotype, as are only $2.5 \%$ of the population. The affected fetus is HPA-1 $(a+b+)$. The father may be HPA- $1(\mathrm{a}+\mathrm{b}+)$ or HPA-1 $(\mathrm{a}+\mathrm{b}-)$. The initial diagnostics of maternal serum samples in experienced laboratories will include screening for platelet alloantibodies using a GPspecific test with test platelets positive for HPA-1a, -1b, -2a, $-2 \mathrm{~b},-3 \mathrm{a},-3 \mathrm{~b},-4 \mathrm{a},-5 \mathrm{a},-5 \mathrm{~b},-15 \mathrm{a},-15 \mathrm{~b}$. Most laboratories also include a screening for HLA class I antibodies, as it cannot be excluded that HLA class I antibodies in very rare cases may be responsible for FNAIT.

Kroll et al. were the first to demonstrate that a pregnant woman may get immunized against a platelet alloantigen with extremely low frequency, which may result from a mutation in one family ("private" antigen) or which may be very rare [60]. If the fetus inherits such a low-frequency antigen from the father, the mother may get immunized.

Table 3: Antibodies identified in 569 cases of FNAIT [59], percentage is indicated for frequencies above $1 \%$.

\begin{tabular}{lrr}
\hline Anti- & $\mathbf{n}$ & Percent \\
\hline HPA-1a & 428 & 75.2 \\
HPA-1b & 3 & \\
HPA-2a & 0 & \\
HPA-2b & 3 & \\
HPA-3a & 10 & 1.8 \\
HPA-3b & 0 & \\
HPA-4a & 0 & \\
HPA-4b & 1 & \\
HPA-5a & 2 & \\
HPA-5b & 101 & 17.8 \\
HPA-15a & 0 & \\
HPA-15b & 2 & \\
HPA-1a + HPA-5b & 13 & 2.3 \\
Antibodies against low-frequency alloantigens & 6 & 1.1 \\
(HPA-8bW, -11bW, -12bW, -13bW [n=2], -14bW) & & \\
& &
\end{tabular}


This maternal antibody will nearly always be missed in an antibody test using a regular platelet screening panel. It will only be found with a platelet serological crossmatch: paternal platelets are tested with maternal serum in a GPspecific immunoassay [60]. In the meantime, many other cases have been discovered using the strategy of including a crossmatch with the MAIPA or another GP-specific assay [61]. It is estimated that approximately $1 \%$ of cases of serologically verified FNAIT is induced by antibodies against low-frequency antibodies (Table 3).

\section{Platelet transfusion and platelet reactive antibodies}

Patients immunized against HLA class I and HPA antigens often experience febrile, nonhemolytic transfusion reactions if they receive incompatible platelet transfusions. Moreover, their post-transfusion platelet increments will be lower than those observed in many nonimmunized patients. This condition of inadequate post-transfusion platelet increments is referred to as refractoriness to platelet transfusions.

HLA class I antibodies are among the most common specificities implicated in febrile transfusion reactions and in platelet transfusion refractoriness, followed by anti-HPA-5b, anti-HPA-1b, anti-HPA-5a, anti-HPA-2b and anti-HPA-1a [62]. The prevalence of HPA specificities in transfused patients differs from the findings in FNAIT, where anti-HPA-1a is the most common antibody. In immunized transfusion recipients, anti-HPA-5b is the most common specificity. Similar observations were made by Schnaidt et al. [63]. HLA class I antibodies can be detected with the lymphocytotoxic test (LCT) [64], but sera of immunized patients often contain additional HLA class I antibodies (not detectable in LCT) with can be found by GP-specific tests. They are at least partly effective in eliciting transfusion reactions and in reducing post-transfusion platelet increments $[62,65]$.

Patients with unacceptably low platelet increments should be subjected to screening assays for HLA class I and additional HPA antibodies, preferably a GP-specific test. With a positive result in screening for HLA class I antibodies, their specificities should be analyzed preferably with a single antigen bead antibody identification assay. Such assays based on the Luminex Multi-Analyte Profiling (xMAP) technology are commercially available (Immucor, Dreieich, Germany; One Lambda/BmT Meerbusch, Germany). For selection of compatible donors, determination of the patient's HLA-A and HLA-B antigens is required. Compatibility can be confirmed with a crossmatch (patient's serum tested with apheresis donor platelets in a GP-specific assay, e.g. MAIPA).

\section{Post-transfusion purpura}

PTP is a rare transfusion reaction occurring almost exclusively in female patients. Approximately 5-9 days after transfusion of RBC concentrates, patients experience a sudden fall of platelet counts, often to extremely low values below 5000/ $\mu \mathrm{L}$. Consequently, these patients are prone to serious bleeding complications. All patients show high-titered platelet alloantibodies, usually against HPA on the GP IIb/IIIa complex. As expected, the patients are negative for the corresponding platelet alloantigens. However, for a limited period of time, their autologous platelets are apparently rapidly eliminated through an immune mechanism. Although first cases of PTP were described 60 years ago $[66,67]$, the pathophysiology of this reaction is still not fully understood [68]. Serologic and clinical findings are paradoxical: during a secondary immune response, patients' B-cell-related immune response shows aspects of autoimmunity. Single patients with PTP have been studied more extensively in an attempt to investigate the nature of this phenomenon. In a patient studied in our laboratory [69] a high-titered HPA-1a antibody was detected, which also reacted with HPA-1 $(a-b+)$ platelets. An eluate prepared from the patient's platelets reacted strongly with HPA-1a(+) platelets. These and additional laboratory findings described in [69] suggest that at least in some patients autoreactive HPA-la-like antibodies exist at least for the limited thrombocytopenic period.

The diagnostic program for the laboratory diagnosis of PTP includes analysis of the HPA alloantibody (GP IIb/ IIIa) and HPA genotyping: the patient should be negative for the corresponding antigen (i.e. HPA-1a(-) in patients with anti-HPA-1a). The HPA antibody concentration is always high; additional HLA class I antibodies may be present. In experienced laboratories, GP(IIb/IIIa)-PAIgG will be tested and an eluate from the patient's platelets.

\section{Passive alloimmune thrombocytopenia (PAT)}

Transfusion of plasma containing platelet alloantibodies results in an immediate fall of platelet counts. This has been observed for anti-HPA-1a [70-72] and anti-HPA-5b [73]. The diagnosis is confirmed by detection of the HPA antibody in the donor's plasma and detection of the corresponding antigen in the recipient. It is therefore essential to exclude plasma donors with HPA antibodies. 


\section{Isoantibodies}

Degos et al. [74] were the first to observe that patients with GT may form antibodies reacting with platelets from healthy subjects. Apparently, the majority of patients with complete deficiency of GP IIb/IIIa (type I GT) due to the underlying mutations of the ITGA2B or ITGB3 gene will develop anti-GPIIb/IIIa isoantibodies [75]. These antibodies will be detected using MAIPA using an appropriate test panel. As they are directed against monomorphic epitopes on GP IIb/IIIa, they will react with all donor platelets irrespective of their HPA-1, -3 and -4 phenotypes. Isoantibody formation in these patients will make platelet transfusions in these patients ineffective. Pregnant women with type I GT who got immunized may give birth to children with immune thrombocytopenia resembling FNAIT: neonatal isoimmune thrombocytopenia [76, 77].

Platelets of individuals of East Asian descent lacking GP IV (CD36) on their platelet membrane may form an isoantibody against this protein. In the original description, this antibody, anti-Nak(a), reacted with platelets of more than $97 \%$ of all Japanese persons tested [78]. Anti$\operatorname{Nak}(\mathrm{a})$ is observed in patients with platelet transfusion refractoriness, and it may induce isoimmune thrombocytopenia in the fetus and newborn [79]. Anti-Nak(a) is easily detected using the PakPlus or PakLx reagents.

\section{Autoantibodies in ITP and acquired thrombasthenia}

In a series pioneering of experiments, Harrington et al. were able to identify a factor in the plasma of patients with ITP, which induced thrombocytopenia in normal subjects [80]. Later, Shulman et al. identified this factor in the immunoglobulin fraction of plasma [81]. Therefore, numerous attempts were made to establish testing for platelet autoantibodies. However, the diagnosis of ITP is still based on clinical criteria excluding other causes for thrombocytopenia.

Investigations on PAIgG (as the "platelet equivalent" to the direct antiglobulin test in RBC autoantibody testing) yielded unsatisfactory results. Elevated levels of PAIgG were identified in patients with both thrombocytopenia of immune or nonimmune origin [82-84]. So PAIgG is of no value as a diagnostic test for ITP and PAIgG that the relatively high quantities of PAIgG are not related to the immune-mediated clearance of platelets in ITP. This is confirmed by the observations made by Kelton and Steeves who found that PAIgG correlates with platelet-associated albumin. The observation by van Leeuwen et al. that autoantibodies in patients with ITP did not react with platelets from patients with GT gave indirect evidence that at least a subset of platelet antibodies react with the GP-IIb/IIIa complex [85].

With the development of GP-specific assays (immunobead assay [35], MAIPA assay [33] and MACE [40]) free platelet autoantibodies and autoantibodies on the patient's autologous platelets can now be determined. Antibodies against GP Ib/IX are as common as against GP IIb/IIIa [86]. This requires moAb against GPs IIb/ IIIa and Ib/IX for antigen immobilization in MAIPA or immunobead assay, which do not interfere with the binding of autoantibodies against these proteins. Using moAb against GP V in MAIPA, autoantibodies against GP V can also be detected. Although GP V is noncovalently associated in the platelet membrane with the GP Ib/IX complex, GP V and GP Ib/IX dissociate if platelets are solubilized with the commonly used nonionic detergents [87]. Therefore, these anti-GP V antibodies are not detected in the assays for GP Ib/X-specific autoantibodies.

In contrast to PAIgG, GP-PAIgG (together with free GP-specific platelet autoantibodies) is a valuable parameter for the diagnosis of ITP. A summary of published data on the sensitivity and specificity of GP-PAIgG (GPs IIb/IIIa and/or Ib/IX) shows that the sensitivity of GPPAIgG for the diagnosis of ITP is $45 \%$ and the specificity is $94 \%$ [88]. The respective figures for free serum antibody are $18 \%$ and $21 \%$ and $96 \%$. These figures confirm data from our group [47]. An alternative to measurement of GP-PAIgG is the analysis of eluates from patients' platelets in platelet immunofluorescence: the presence of platelet reactive autoantibodies in the eluate correlates with GP-PAIgG [47]. In assays for GP-PAIgG, it seems to be sufficient to test for IgG autoantibodies. IgM and IgG autoantibodies sometimes occur but in most patients they are found together with IgG autoantibodies [47]. From these data, it can be concluded that negative results for platelet autoantibodies do not preclude the diagnosis of ITP, whereas cell-bound or free platelet autoantibodies against GPs IIb/IIIa, Ib/IX or V are a specific finding for ITP.

In rare cases, patients present with autoantibodies against GP IIb/IIIa which lead to impairment of platelet function rather than thrombocytopenia. The first case was described by Niessner et al. [89]. In the meantime, more cases with acquired thrombasthenia have been described, often associated with lymphatic malignancies [90]. Some patients shift from thrombocytopenic phases 
and phases with GT-like platelet function defects (and normal platelet counts). The antibody can be assessed by direct MAIPA, and its functional effects by light-transmission aggregometry (LTA) according to Born applied to the patient's platelets.

\section{Drug-induced immune thrombocytopenia: drug-dependent antibodies}

Drugs may cause thrombocytopenia due to toxic effects; this occurs typically with chemotherapeutic agents. DIT is a peculiar form of immune thrombocytopenia. It is known for a long time, but its mechanism has remained unclear. Early clinical observations on quinine date back to 1928 , and attempts for laboratory investigation were made in 1948 (cited in [91]). DIT occurs not earlier than 7 days after the first administration of a drug; however, relapse may occur within hours if an "immunized" patient with circulating antibodies is reexposed to the drug. Thrombocytopenia may be severe with a rapid fall of platelet count. If quinine/quinidine type of DIT is suspected, detection of DDAB confirms the diagnosis [92]. DDAB testing requires a lot of expertise so it is only available in a few specialized laboratories.

As already described, DDAB may be tested in immunoglobulin binding assays with intact platelets, e.g. a quantitative enzyme immunoassay [53] or an ELISA with suspended platelets. Like normal autoantibodies, DDAB may specifically react with platelet GPs Ib/IX or IIb/IIIa. This was suggested by the observation of van Leeuwen et al. that quinine and quinidine-reactive antibodies reacting with normal platelets did not react with platelets from patients with Bernard-Soulier-Syndrome which are known for their deficiency of (components of) the GP Ib/IX complex. Consequently, DDAB can be tested using MAIPA modified for the detection of antibodies in the presence of the drug [92].

In principle, many compounds are able to trigger DIT. Among the drugs which could be confirmed by positive tests for DDAB in the author's lab in cases of DIT are quinine, quinidine, trimethoprim-sulfamethoxazole, paracetamol, carbamazepine, diclofenac, ibuprofen, vancomycin, eptifibatide and ampicillin. A large list of drugs implicated in DIT can be found in a database maintained by George [93].

Sometimes, administration of drugs induces platelet autoantibodies, similar to those found in ITP. This has been observed in patients receiving gold salts $[94,95]$. The principal target for autoantibodies in gold-induced ITP is GP V [96].
A completely different drug reaction affecting platelets is HIT. It is much more common than quinine-type DIT and has a different pathophysiology. Moreover, HIT has different clinical features: in contrast to patients with DIT who are prone to bleeding complications, patients with HIT are endangered by thromboembolic complications. The initial diagnosis is based on clinical data ("4T score" [97]) and immunoassays for platelet factor 4 (PF4)-heparin complexes [98]. Laboratory confirmation requires functional assays: ${ }^{14} \mathrm{C}$ serotonin release assay [6] or the HIPA assay published by Greinacher et al. [7].

\section{Conclusions}

Platelet antibodies play an essential role in a variety of situations with disturbed primary hemostasis. The diagnosis of ITP is supported by the detection of antibodies against GPs IIb/IIIa, Ib/IX and V. GP-IIb/IIIa-specific platelet autoantibodies impairing platelet function are a specific finding in acquired thrombasthenia. In alloimmunized thrombocytopenic patients, platelet transfusions will only be effective, if these patients receive platelet concentrates from selected donors who are negative for the respective HPA or HLA class I antigens. Here, platelet crossmatch tests are required to confirm immunologic compatibility. In hospitalized patients, who receive blood transfusions and various medications and who experience a sudden fall of platelet counts within hours or a few days, acute ITP, DIT and PTP should be considered. In fetal and neonatal thrombocytopenia, maternal IgG alloantibodies should be considered as a possible cause. Diagnosis of these maternal alloantibodies will help to predict the risk for a fetus of a future pregnancy. GP-specific immunoassays are, with only a few exceptions, state of the art in platelet antibody testing. New technologies, including cell lines carrying HPA antigens with high density and assays allowing detection of low-avidity HPA antibodies, are currently developed.

Author contributions: Not applicable: one author.

Research funding: None declared.

Employment or leadership: None declared.

Honorarium: None declared.

Competing interests: Author state no conflict of interest.

Informed consent: Not applicable.

Ethical approval: Not applicable. 


\section{References}

1. von dem Borne AE, Decary F. ICSH/ISBT working party on platelet serology. Nomenclature of platelet-specific antigens. Vox Sang 1990;58:176.

2. Santoso S, Kiefel V. Human platelet-specific alloantigens: update. Vox Sang 1998;74 (Suppl. 2):249-53.

3. van der Weerdt CM. The platelet agglutination test in platelet grouping. In: Histocompatibility testing 1965 . Copenhagen: Munksgaard, 1965:161-6.

4. Shulman NR, Marder VJ, Hiller MC, Collier EM. Platelet and leukocyte isoantigens and their antibodies: serologic, physiologic and clinical studies. In: Moore CV, Brown EB, editors. Progress in hematology. Vol. IV. New York: Grune \& Stratton, 1964:222-304.

5. Hirschmann RJ, Shulman NR. The use of platelet serotonin release as a sensitive method for detecting anti-platelet antibodies and a plasma anti-platelet factor in patients with idiopathic thrombocytopenic purpura. Br J Haematol 1973;24:793-802.

6. Sheridan D, Carter C, Kelton JG. A diagnostic test for heparininduced thrombocytopenia. Blood 1986;67:27-30.

7. Greinacher A, Michels I, Kiefel V, Mueller-Eckhardt C. A rapid and sensitive test for diagnosing heparin-associated thrombocytopenia. Thromb Haemost 1991;66:734-6.

8. Coombs RR, Mourant AE, Race RR. A new test for the detection of weak and "incomplete" $\mathrm{Rh}$ agglutinins. $\mathrm{Br} J$ Exp Pathol 1945;26:255-66.

9. Mueller-Eckhardt C, Mahn I, Schulz G, Mueller-Eckhardt G. Detection of platelet autoantibodies by a radioactive anti-immunoglobulin test. Vox Sang 1978;35:357-65.

10. Kiefel V, Santoso S. Nachweis von thrombozytären Antigenen und Antikörpern. In: Kiefel V, editor. Transfusionsmedizin und Immunhämatologie, 4th ed. Berlin, Heidelberg: Springer, 2010:591-5.

11. von dem Borne AE, Verheugt FW, Oosterhof F, von Riesz E, Brutel de la Riviere A, Engelfriet CP. A simple immunofluorescence test for the detection of platelet antibodies. Br J Haematol 1978;39:195-207.

12. Helmerhorst FM, Smeenk TJ, Hack CA, Engelfriet CP, von dem Borne $A E$. Interference of IgG, IgG aggregates and immune complexes in tests for platelet autoantibodies. $\mathrm{Br} J$ Haematol 1983;55:533-45.

13. Schneider W, Schnaidt M. The platelet adhesion immunofluorescence test: a modification of the platelet suspension immunofluorescence test. Blut 1981;43:389-92.

14. Shibata Y, Juji T, Nishizawa Y, Sakamoto H, Ozawa N. Direction of platelet antibodies by a newly developed mixed agglutination with platelets. Vox Sang 1981;41:25-31.

15. Matsuhashi M, Tsuno H. Laboratory testing for the diagnosis of immune-mediated thrombocytopenia. Ann Blood 2018; 4:1-10.

16. Nordhagen R, Flaathen ST. Chloroquine removal of HLA antigens from platelets for the platelet immunofluorescence test. Vox Sang 1985;48:156-9.

17. Curtis BR, Edwards JT, Hessner MJ, Klein JP, Aster RH. Blood group $A$ and $B$ antigens are strongly expressed on platelets of some individuals. Blood 2000;96:1574-81.

18. Cooling LL, Kelly K, Barton J, Hwang D, Koerner TA, Olson JD. Determinants of $\mathrm{ABH}$ expression on human blood platelets. Blood 2005;105:3356-64.
19. Santoso S, Kiefel V, Mueller-Eckhardt C. Blood group A and B determinants are expressed on platelet glycoproteins Ila, IIla, and Ib. Thromb Haemost 1991;65:196-201.

20. Hou M, Stockelberg D, Rydberg L, Kutti J, Wadenvik H. Blood group $A$ antigen expression in platelets is predominantly associated with glycoprotein $\mathrm{lb}$ and Ilb. Evidence for an A(1)/A(2) difference. Transfus Med 1996;6:51-9.

21. Morse BS, Giuliani D, Nussbaum M. Quantitation of plateletassociated IgG by radial immunodiffusion. Blood 1981;57: 809-11.

22. Kelton JG, Steeves K. The amount of platelet-bound albumin parallels the amount of IgG on washed platelets from patients with immune thrombocytopenia. Blood 1983;62:924-7.

23. Dixon R, Rosse WF, Ebbert L. Quantitative determination of antibody in idiopathic thrombocytopenic purpura. Correlation of serum and platelet-bound antibody with clinical response. $\mathrm{N}$ Engl J Med 1975;292:230-6.

24. Kiefel V, Jäger S, Mueller-Eckhardt C. Competitive enzyme-linked immunoassay for the quantitation of platelet-associated immunoglobulins (IgG, IgM, IgA) and complement (C3C, C3d). Vox Sang 1987;53:151-6.

25. Follea G, Mandrand B, Dechavanne M. Simultaneous enzymoimmunologic assays of platelet associated IgG, IgM, and C3. A useful tool in assessment of immune thrombocytopenias. Thromb Res 1982;26:249-58.

26. Kelton JG, Denomme G. An immunoradiometric assay for quantitating platelet-associated IgG. In: McMillan R, editors. Immune cytopenias. New York: Churchill Livingstone, 1983:197-213.

27. Warner M, Kelton JG. Laboratory investigation of immune thrombocytopenia. J Clin Pathol 1997;50:5-12.

28. Huisman JG. Immunoblotting: an emerging technique in immunohematology. Vox Sang 1986;50:129-36.

29. Santoso S, Kiefel V, Mueller-Eckhardt C. Immunochemical characterization of the new platelet alloantigen system $\mathrm{Br}(\mathrm{a}) / \mathrm{Br}(\mathrm{b})$. Br J Haematol 1989;72:191-8.

30. Kelton JG, Smith JW, Horsewood P, Humbert JR, Hayward CP, Warkentin TE. Gov(a)/Gov(b) alloantigen system on human platelets. Blood 1990;75:2172-6.

31. Woods VL, Oh EH, Mason D, McMillan R. Autoantibodies against the platelet glycoprotein IIb/IIla complex in patients with chronic ITP. Blood 1984;63:368-75.

32. Woods VL, Kurata Y, Montgomery RR, Tani P, Mason D, Oh $\mathrm{EH}$, et al. Autoantibodies against platelet glycoprotein $\mathrm{Ib}$ in patients with chronic immune thrombocytopenic purpura. Blood 1984;64:156-60.

33. Kiefel V, Santoso S, Weisheit M, Mueller-Eckhardt C. Monoclonal antibody-specific immobilization of platelet antigens (MAIPA): a new tool for the identification of platelet reactive antibodies. Blood 1987;70:1722-6.

34. Kiefel V. The MAIPA assay and its applications in immunohematology. Transfus Med 1992;2:181-8.

35. McMillan R, Tani P, Millard F, Berchtold P, Renshaw L, Woods VL. Platelet-associated and plasma anti-glycoprotein autoantibodies in chronic ITP. Blood 1987;70:1040-5.

36. Bux J, Kober B, Kiefel V, Mueller-Eckhardt C. Analysis of granulocyte-reactive antibodies using an immunoassay based upon monoclonal-antibody-specific immobilization of granulocyte antigens. Transfus Med 1993;3:157-62.

37. Giltay JC, Brinkman HJ, Vlekke A, Kiefel V, van Mourik JA, von dem Borne AE. The platelet glycoprotein la-Ila-associated 
Br-alloantigen system is expressed by cultured endothelial cells. Br J Haematol 1990;75:557-60.

38. Petty AC, Daniels GL, Anstee DJ, Tippett P. Use of the MAIEA technique to confirm the relationship between the Cromer antigens and decay-accelerating factor and to assign provisionally antigens to the short-consensus repeats. Vox Sang 1993;65:309-15.

39. Mueller-Eckhardt G, Kiefel V, Schmidt A, Tlusty A, Santoso $S$, Mueller-Eckhardt C. Discrimination of antibodies against antigens of different MHC loci in human sera by monoclonal antibody-specific immobilization of leukocyte antigens. Hum Immunol 1989;25:125-34.

40. Menitove JE, Pereira J, Hoffman R, Anderson T, Fried W, Aster RH. Cyclic thrombocytopenia of apparent autoimmune etiology. Blood 1989;73:1561-9.

41. Nguyen XD, Dugrillon A, Beck C, Kerowgan M, Kluter H. A novel method for simultaneous analysis of specific platelet antibodies: SASPA. Br J Haematol 2004;127:552-60.

42. Porcelijn L, Huiskes E, Comijs-van Osselen I, Chhatta A, Rathore V, Meyers M, et al. A new bead-based human platelet antigen antibodies detection assay versus the monoclonal antibody immobilization of platelet antigens assay. Transfusion 2014;54:1486-92.

43. Cooper N, Bein G, Heidinger K, Santoso S, Sachs UJ. A beadbased assay in the work-up of suspected platelet alloimmunization. Transfusion 2016;56:115-8.

44. Socher I, Andrei-Selmer C, Bein G, Kroll H, Santoso S. Low-avidity HPA-1a alloantibodies in severe neonatal alloimmune thrombocytopenia are detectable with surface plasmon resonance technology. Transfusion 2009;49:943-52.

45. Zhang N, Santoso S, Aster RH, Curtis BR, Newman PJ. Bioengineered iPSC-derived megakaryocytes for the detection of platelet-specific patient alloantibodies. Blood 2019;134:e1-8.

46. Koh Y, Nishimiya H, Inoue H, Kishigami A, Tsuji Y, Sakamoto R, et al. A novel simple assay system for the detection of human platelet antigen 15 (HPA-15) alloantibodies based on three techniques: an HPA-15 expressing cell line, a monoclonal antibody-specific antigen-capture method and mixed-passive haemagglutination. Vox Sang 2020;115:202-6.

47. Kiefel V, Freitag E, Kroll H, Santoso S, Mueller-Eckhardt C. Platelet autoantibodies (IgG, IgM, IgA) against glycoproteins IIb/ IIIa and Ib/IX in patients with thrombocytopenia. Ann Hematol 1996;72:280-5.

48. Bertrand G, Jallu V, Gouet M, Kjaer KM, Lambin P, Husebekk A, et al. Quantification of human platelet antigen-1a antibodies with the monoclonal antibody immobilization of platelet antigens procedure. Transfusion 2005;45:1319-23.

49. Killie MK, Salma W, Bertelsen E, Skogen B, Husebekk A. Quantitative MAIPA: comparison of different MAIPA protocols. Transfus Apher Sci 2010;43:149-54.

50. Sainio S, Javela K, Tuimala J, Koskinen S. Usefulness of maternal anti-HPA-1a antibody quantitation in predicting severity of foetomaternal alloimmune thrombocytopenia. Transfus Med 2013;23:114-20.

51. Newman PJ, Derbes RS, Aster RH. The human platelet alloantigens, $\mathrm{Pl}(\mathrm{A} 1)$ and $\mathrm{Pl}(\mathrm{A} 2)$, are associated with a leucine(33)/ proline(33) amino acid polymorphism in membrane glycoprotein IIIa, and are distinguishable by DNA typing. J Clin Invest 1989;83:1778-81.

52. Eisner EV, Kasper K. Immune thrombocytopenia due to a metabolite of para-aminosalicylic acid. Am J Med 1972;53:790-6.
53. Kiefel V, Santoso S, Schmidt S, Salama A, Mueller-Eckhardt C. Metabolite-specific (IgG) and drug-specific antibodies (IgG, IgM) in two cases of trimethoprim-sulfamethoxazole-induced immune thrombocytopenia. Transfusion 1987;27:262-5.

54. Kao KJ, Cock DJ, Scornick JC. Quantitative analysis of platelet surface HLA by w6/32 anti-HLA monoclonal antibody. Blood 1986;68:627-32.

55. Kiefel V, Kroll H, Bonnert J, Unkelbach K, Katzmann B, Nebenführer Z, et al. Platelet alloantigen frequencies in Caucasians: a serological study. Transfus Med 1993;3:237-42.

56. Shibata Y, Miyaji T, Ichikawa Y, Matsuda I. A new platelet antigen system, Yuk(a)/Yuk(b). Vox Sang 1986;51:334-6.

57. Berry JE, Murphy CM, Smith GA, Ranasinghe E, Finberg R, Walton J, et al. Detection of Gov system antibodies by MAIPA reveals an immunogenicity similar to the HPA-5 alloantigens. $\mathrm{Br} J$ Haematol 2000;110:735-42.

58. Peterson JA, McFarland JG, Curtis BR, Aster RH. Neonatal alloimmune thrombocytopenia: pathogenesis, diagnosis and management. Br J Haematol 2013;161:3-14.

59. Kroll H, Yates J, Santoso S. Immunization against a low-frequency human platelet alloantigen in fetal alloimmune thrombocytopenia is not a single event: characterization by the combined use of reference DNA and novel allele-specific cell lines expressing recombinant antigens. Transfusion 2005;45:353-8.

60. Kroll H, Kiefel V, Santoso S, Mueller-Eckhardt C. Sr(a), a private platelet antigen on glycoprotein IIla associated with neonatal alloimmune thrombocytopenia. Blood 1990;76:2296-302.

61. Curtis BR, McFarland JG. Human platelet antigens - 2013. Vox Sang 2014;106:93-102.

62. Kiefel V, König C, Kroll H, Santoso S. Platelet alloantibodies in transfused patients. Transfusion 2001;41:766-70.

63. Schnaidt M, Northoff $H$, Wernet D. Frequency and specificity of platelet-specific alloantibodies in HLA-immunized haematologic-oncologic disorders. Transfus Med 1996;6:111-4.

64. Terasaki PI, McClelland JD. Microdroplet assay of human serum cytotoxins. Nature 1964;204:998-1000.

65. Kurz M, Greinix H, Höcker P, Kahls P, Mayr WR, Pober M, et al. Specificities of anti-platelet antibodies in multitransfused patients with haemato-oncological disorders. $\mathrm{Br} J$ Haematol 1996;95:564-9.

66. van Loghem JJ, Dorfmeijer H, van der Hart M, Schreuder F. Serological and genetical studies on a platelet antigen (Zw). Vox Sang 1959;4:161-9.

67. Shulman NR, Aster RH, Leithner A, Hiller MC. Immunoreactions involving platelets. V. Post-transfusion purpura due to a complement-fixing antibody against a genetically controlled platelet antigen. A proposed mechanism for thrombocytopenia and its relevance in "autoimmunity". J Clin Invest 1961;40:1597-620.

68. Hawkins J, Aster RH, Curtis BR. Post-transfusion purpura: current perspectives. J Blood Med 2019;10:405-15.

69. Kiefel V, Schönberner-Richter I, Schilf K. Anti-HPA-1a in a case of post-transfusion purpura: binding to antigen-negative platelets detected by adsorption/elution. Transfus Med 2005;5:243-7.

70. Scott EP, Moilan-Bergeland J, Dalmasso AP. Posttransfusion thrombocytopenia associated with passive transfusion of a platelet-specific antibody. Transfusion 1988;28:73-6.

71. Brunner-Bollinger S, Kiefel V, Horber FF, Nydegger UE, Berchtold $P$. Antibody studies in a patient with acute thrombocytopenia following infusion of plasma containing anti-PI(A1). Am J Hematol 1997;56:119-21. 
72. Pavenski K, Webert KE, Goldman M. Consequences of transfusion of platelet antibody: a case report and literature review. Transfusion 2008;48:1981-9.

73. Warkentin TE, Smith JW, Hayward CP, Ali AM, Kelton JG. Thrombocytopenia caused by passive transfusion of anti-glycoprotein la/Ila alloantibody (anti-HPA-5b). Blood 1992;79:2480-4.

74. Degos L, Dautigny A, Brouet JC, Colombani M, Ardaillou N, Caen JP, et al. A molecular defect in thrombasthenic platelets. J Clin Invest 1975;56:236-40.

75. Fiore M, Firah N, Pillois X, Nurden P, Heilig R, Nurden AT. Natural history of platelet antibody formation against alphallbbeta3 in a French cohort of Glanzmann thrombasthenia patients. Haemophilia 2012;18:e201-9.

76. Kiefel V, Meyer E, Greinacher A, Kroll H, Mueller-Eckhardt C. Neonatale isoimmunthrombozytopenie durch Anti-GP IIb/IIla. In: Kretschmer V, Stangel W, Wiebecke D, editors. Transfusionsmedizin 1991/92. Basel: Karger, 1992:450-3.

77. Leticee N, Kaplan C, Lemery D. Pregnancy in mother with Glanzmann's thrombasthenia and isoantibody against GPIIbIIla: is there a foetal risk? Eur J Obstet Gynecol Reprod Biol 2005;121:139-42.

78. Ikeda H, Mitani T, Ohnuma M, Haga H, Ohtzuka S, Kato T, et al. A new platelet-specific antigen, $\operatorname{Nak}(a)$, involved in the refractoriness of HLA-matched platelet transfusion. Vox Sang 1989;57:213-7.

79. Curtis BR, Ali S, Glazier AM, Ebert DD, Aitman TJ, Aster RH. Isoimmunization against CD36 (glycoprotein IV): description of four cases of neonatal isoimmune thrombocytopenia and brief review of the literature. Transfusion 2002;42:1173-9.

80. Harrington WJ, Minnich V, Hollingsworth JW, Moore CV. Demonstration of a thrombocytopenic factor in the blood of patients with thrombocytopenic purpura. J Lab Clin Med 1951;38:1-10.

81. Shulman NR, Marder VJ, Weinrach RS. Similarities between known antiplatelet antibodies and the factor responsible for thrombocytopenia in idiopathic purpura. Physiologic, serologic and isotopic studies. Ann N Y Acad Sci 1965;124:499-542.

82. Mueller-Eckhardt C, Kayser W, Mersch-Baumert K, Mueller-Eckhardt G, Breidenbach M, Kugel HG, et al. The clinical significance of platelet-associated IgG: a study on 298 patients with various disorders. Br J Haematol 1980;46:123-31.

83. Kiefel V, Spaeth P, Mueller-Eckhardt C. Immune thrombocytopenic purpura: autoimmune or immune complex disease? $\mathrm{Br}$ J Haematol 1986;64:57-68.

84. Warner MN, Moore JC, Warkentin TE, Santos AV, Kelton JG. A prospective study of protein-specific assays used to investigate idiopathic thrombocytopenic purpura. $\mathrm{Br} J$ Haematol 1999;104:442-7.

85. van Leeuwen EE, van der Ven JT, Engelfriet CC, von dem Borne AE. Specificity of autoantibodies in autoimmune thrombocytopenia. Blood 1982;59:23-6.
86. Kiefel V, Santoso S, Kaufmann E, Mueller-Eckhardt C. Autoantibodies against platelet glycoprotein Ib/IX: a frequent finding in autoimmune thrombocytopenic purpura. Br J Haematol 1991;79:256-62.

87. Modderman PW, Admiraal LG, Sonnenberg A, von dem Borne AE. Glycoproteins V and Ib-IX form a noncovalent complex in the platelet membrane. J Biol Chem 1992;267:364-9.

88. Vrbensky JR, Moore JE, Arnold DM, Smith JW, Kelton JG, Nazy I. The sensitivity and specificity of platelet autoantibody testing in immune thrombocytopenia: a systematic review and meta-analysis of a diagnostic test. J Thromb Haemost 2019;17:787-94.

89. Niessner H, Clemetson KJ, Panzer S, Mueller-Eckhardt C, Santoso S, Bettelheim P. Acquired thrombasthenia due to GP IIb/ IIla-specific autoantibodies. Blood 1986;68:571-6.

90. Porcelijn L, Huiskes E, Maatman R, de Kreuk A, de Haas M. Acquired Glanzmann's thrombasthenia caused by glycoprotein IIb/IIla autoantibodies of the immunoglobulin G1 (IgG1), IgG2 or IgG4 subclass: a study in six cases. Vox Sang 2008;95: 324-30.

91. Shulman NR, Jordan JV. Platelet immunology. In: Colman RW, Hirsh J, Marder VJ, Salzman EW, editors. Hemostasis and thrombosis. Basic principles and practice. Philadelphia: Lippincott, 1987:452-529.

92. Arnold DM, Kukaswadia S, Nazi I, Esmail A, Dewar L, Smith JW, et al. A systematic evaluation of laboratory testing for drug-induced immune thrombocytopenia. J Thromb Haemost 2013;11:169-76.

93. George JN. Drug-induced thrombocytopenia (alectronic document, accessed January 19th, 2020). https://www.ouhsc.edu/ platelets/ditp.html. 2015

94. von dem Borne AE, Pegels JG, van der Stadt RJ, van der Plas-van Dalen CM, Helmerhorst FM. Thrombocytopenia associated with gold therapy: a drug-induced autoimmune disease. $\mathrm{Br} J$ Haematol 1986;63:509-16.

95. Andres E, Dali-Youcef N, Serraj K, Zimmer J. Recognition and management of drug-induced cytopenias: the example of idiosyncratic drug-induced thrombocytopenia. Expert Opin Drug Saf 2009;8:183-90.

96. Garner SF, Campbell K, Metcalfe P, Keidan J, Huiskes E, Dong JF, et al. Glycoprotein V: the predominant target antigen in gold-induced autoimmune thrombocytopenia. Blood 2002;100:344-6.

97. Lo GK, Juhl D, Warkentin TE, Sigoun CS, Eichler P, Greinacher A. Evaluation of pretest clinical score (4 T's) for the diagnosis of heparin-induced thrombocytopenia in two clinical settings. J Thromb Haemost 2006;4:759-65.

98. Amiral J, Bridey F, Dreyfus M, Vissac AM, Fressinaud E, Wolf M, et al. Platelet factor 4 complexed to heparin is the target for antibodies generated in heparin-induced thrombocytopenia [letter]. Thromb Haemost 1992;68:95-6. 